\title{
Thioarsenate formation in paddy soils
}

\author{
J. Wang ${ }^{1}$, M. Romani ${ }^{2}$, M. Martin ${ }^{3}$ \& B. Planer-Friedrich ${ }^{1}$ \\ ${ }^{1}$ Environmental Geochemistry, Bayreuth University, Bayreuth, Germany \\ ${ }^{2}$ Ente Nazionale Risi, Milan, Italy \\ ${ }^{3}$ Dipartimento di Scienze Agrarie, Forestali e Alimentari, University of Torino, Turin, Italy
}

\begin{abstract}
Despite the significance of sulfur in controlling arsenic cycling, thioarsenate formation has not been studied in paddy soils, yet. Here, we combined lab incubation experiments with field porewater sampling from two Italian paddy soils to assess the geochemical significance of thioarsenate. Incubation data showed formation of both inorganic and methylated thioarsenates under flooded conditions, even in the absence of extra sulfate addition. Percentages of total arsenic were $12.5 \%$ and $18.3 \%$, respectively. All species were also discovered after draining the systems for 4 days and re-flooding. Field sampling at rice flowering stage further confirmed the existence of inorganic (average 22.3\%) and methylated thioarsenates (average 2.2\%) under natural conditions. In summary, since our results conclusively prove the occurrence and quantitative importance of thioarsenate in paddy soils, their environmental fate urgently needs to be addressed.
\end{abstract}

\section{INTRODUCTION}

Elevated arsenic (As) concentrations in rice grains pose a serious health risk for over half the global population (Meharg et al., 2009). Over the past years, knowledge about arsenite, arsenate, and methylated arsenates has increased tremendously. However, the formation of soluble arsenic-sulfur complex, so-called thio-arsenates $\left(\mathrm{As}^{\mathrm{V}} \mathrm{S}^{0} \mathrm{~S}_{\mathrm{n}}^{-\mathrm{II}} \mathrm{O}_{4-\mathrm{n}}^{3-}\right.$, with $\left.\mathrm{n}=0-3\right)$, has never been studied in rice agroecosystems, despite the long-recognized significance of reduced sulfur ligands in controlling aqueous metal speciation (Boulegue et al., 1982). The neglectance of considering thioarsenates is partially explained because acidification, which is both used for stabilization as well as for chromatographic separation, leads to precipitation of AsSminerals (Smieja \& Wilkin, 2003) and transformation of thioarsenates (Planer-Friedrich \& Wallschläger, 2009). Using flash-freezing for sample stabilization and chromatographic separation in an alkaline eluent as analytical method (Planer-Friedrich et al., 2007), we have very recently gathered preliminary evidence from Italian and French rice fields revealing that inorganic and methylated thioarsenate do occur under natural conditions. In the present study, two Italian paddy soils were selected to elucidate the formation of thioarsenate via lab incubations. Porewater samples were also taken in the open fields at rice flowering stage to further assess the geochemical significance of thioarsenate in rice agroecosystems.

\section{METHODS/EXPERIMENTAL}

The paddy soils were sampled from two farms "Cascina Veronica" and "Cascina Formazzo" in
Mortara (Italy). For each microcosm, $400 \mathrm{~g}$ fresh soil $(2 \mathrm{~mm}$ sieved) were premixed with $2.5 \mathrm{~g}$ rice straw, then $250 \mathrm{~mL}$ tap water was added. Microcosms ( $500 \mathrm{~mL}$ polyethylene bottles) were equipped with rhizonsamplers and connected to a Teflon shut-off valve. No additional sulfate was added during the first 20 days of flooding. Thereafter, soils were drained and oxidation was allowed to occur for 4 days. Oxidized soils were then reflooded for 14 days with tap water containing $1 \mathrm{mM}\left(\mathrm{NH}_{4}\right)_{2} \mathrm{SO}_{4}$, thus to mimic the sulfate fertilizer application practice in Italy. Additionally, three porewater samples from each farm were taken at rice flowering stage. Porewater $\mathrm{E}_{\mathrm{H}}$ and $\mathrm{pH}$ were measured following standard protocol. Iron was measured photometrically by the ferrozine assay and free sulfide by the methylene blue method. Aqueous arsenic and sulfur speciation was analyzed by anion exchange chromatography (Dionex ICS-3000 SP) ICP-MS without suppressor, following the method of Wallschläger and London (2007).

\section{RESULTS AND DISCUSSION}

\subsection{Thioarsenate formation under flooding-drainage-reflooding}

Besides arsenite, arsenate, monomethylarsenate (MMA), and dimethylarsenate (DMA), nine other As species were detected in both soils after flooding. Three of those species were confirmed as inorganic thioarsenates (thioAs), specifically mono(MTA), di- (DTA) and trithioarsenate (TTA). Another three were identified as methylated thioarsenates (MethylthioAs), namely monomethylmonothioarsenate (MMMTA), monomethyldithioarsenate 


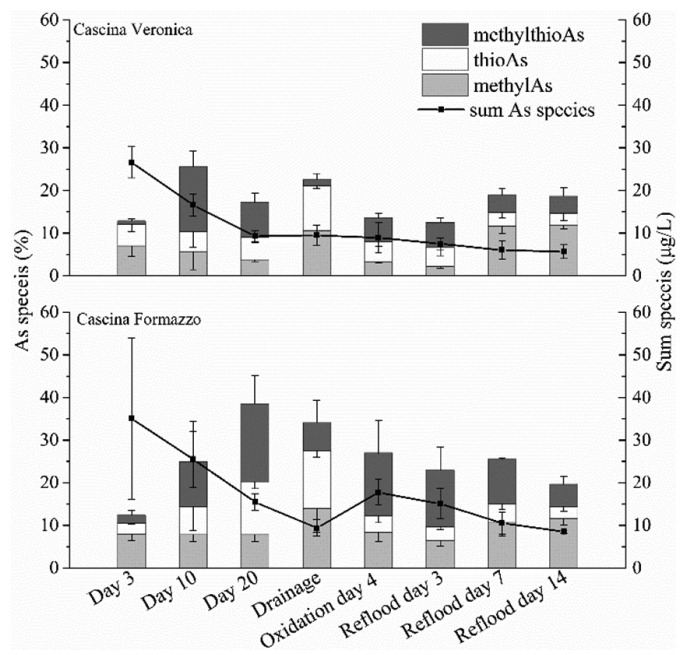

Figure 1. Porewater As speciation under flooding-drainagereflooding cycling.

(MMDTA), and dimethyldithioarsenate (DMDTA). Additionally, we detected 3 unknown peaks with general abundance $<1 \%$.

Relative abundance of thioAs peaked after 20 days flooding in both Veronica and Formazzo soils (Fig. 1) with $5.3 \pm 1.3 \%$ and $12.5 \pm 1.2 \%$, respectively. Relative abundance of methylthioAs peaked at day 10 for Veronica and day 20 for Formazzo (Fig. 1), with $15.2 \pm 3.7 \%$ and $18.3 \pm 6.5 \%$, respectively.

Interestingly, higher percentages of thioAs were found in the drainage when compared that of porewater at day 20 in both soils (Fig. 1). This observation could indicate less absorption of thioAs to the soil solid phase, probably due to less affinity of thioAs to $\mathrm{Fe}$ minerals as suggested by previous studies (Couture et al., 2013). All species were also discovered after reflooding, though in different shares. Since free sulfide was below detection limit under flooded conditions, we speculate it is elemental sulfur formation which determines As thiolation (Planer-Friedrich et al., 2015).

\subsection{Arsenic speciation in field samples}

MethylthioAs species were of minor quantitative importance, except in sample Formazzo-1, with an average percentage of $2.2 \%$. The main As species in Veronica porewater were arsenate $(34.4 \pm 5.9 \%)$, arsenite $(18.4 \pm 6.0 \%)$, MTA $(17.1 \pm 1.1 \%)$, DTA $(13.0 \pm 3.3 \%), \quad$ DMA $(12.8 \pm 6.8 \%)$ and MMA $(1.8 \pm 1.2 \%)$. In Formazzo, the main porewater As species detected were arsenite $(59.8 \pm 7.9 \%)$, arsenate $(19.1 \pm 5.4 \%)$, DTA $(10.9 \pm 7.7 \%)$, DMA $(3.5 \pm 1.8 \%)$, MTA $(1.4 \pm 0.8 \%)$, and MMA $(1.8 \pm$ $2.3 \%)$. TTA $(1.3 \pm 0.9)$. The percentage of the thioAs (average $22.3 \%$ ) was found to outweight that of methylate arsenate (average 9.7\%) in all the porewater samples (Fig. 2).

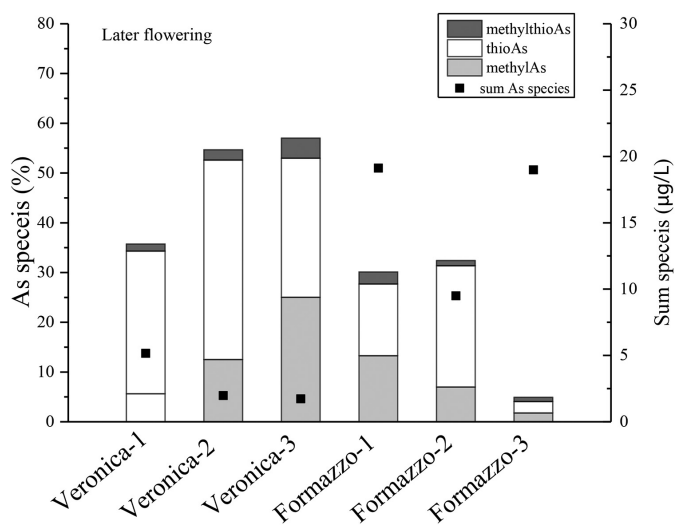

Figure 2. Porewater As speciation at rice flowering stage at fields.

\section{CONCLUSIONS}

Our lab experimental and field sampling data conclusively prove the occurrence and quantitative importance of inorganic and methylated thioarsenates in rice agroecosystems. Given the ubiquitous natural occurrence of arsenic and sulfur in reduced paddy soils, As thiolation needs to be considered in future As cycling studies.

\section{REFERENCES}

Boulegue, J., Lord, C.J. \& Church, T.M. 1982. Sulfur speciation and associated trace metals $(\mathrm{Fe}, \mathrm{Cu})$ in the pore waters of Great Marsh, Delaware. Geochim. Cosmochim. Acta 46(30): 453-464.

Couture, R.-M., Rose, J., Kumar, N., Mitchell, K., Wallschläger, D. \& Van Cappellen, P. 2013. Sorption of arsenite, arsenate, and thioarsenates to iron oxides and iron sulfides: a kinetic and spectroscopic investigation. Environ. Sci. Technol. 47(11): 5652-5659.

Meharg, A.A., Williams, P.N., Adomako, E., Lawgali, Y.Y., Deacon, C., Villada, A., Cambell, R.C., Sun, G., Zhu, Y.-G. \& Feldmann, J. 2009. Geographical variation in total and inorganic arsenic content of polished (white) rice. Environ. Sci. Technol. 43(5): 1612-1617.

Planer-Friedrich, B. \& Wallschläger, D. 2009. A critical investigation of hydride generation-based arsenic speciation in sulfidic waters. Environ. Sci. Technol. 43(13): 5007-5013.

Planer-Friedrich, B., London, J., McCleskey, R.B., Nordstrom, D.K. \& Wallschläger, D. 2007. Thioarsenates in geothermal waters of Yellowstone national park: determination, preservation, and geochemical importance. Environ. Sci. Technol. 41(15): 5245-5251.

Planer-Friedrich, B., Hartig, C., Lohmayer, R., Suess, E., McCann, S. \& Oremland, R. 2015. Anaerobic chemolithotrophic growth of the haloalkaliphilic bacterium strain MLMS-1 by disproportionation of monothioarsenate. Environ. Sci. Technol. 49(11): 6554-6563.

Smieja, J.A. \& Wilkin, R.T. 2003. Preservation of sulfidic waters containing dissolved As(III). J. Environ. Monit 5(6): 913-916.

Wallschläger, D. \& London, J. 2007. Determination of methylated arsenic-sulfur compounds in groundwater. Environ. Sci. Technol. 42(1): 228-234. 